\title{
Focus on Fathers for Promoting Safe Sleep and Breastfeeding
}

Alison Jacobson

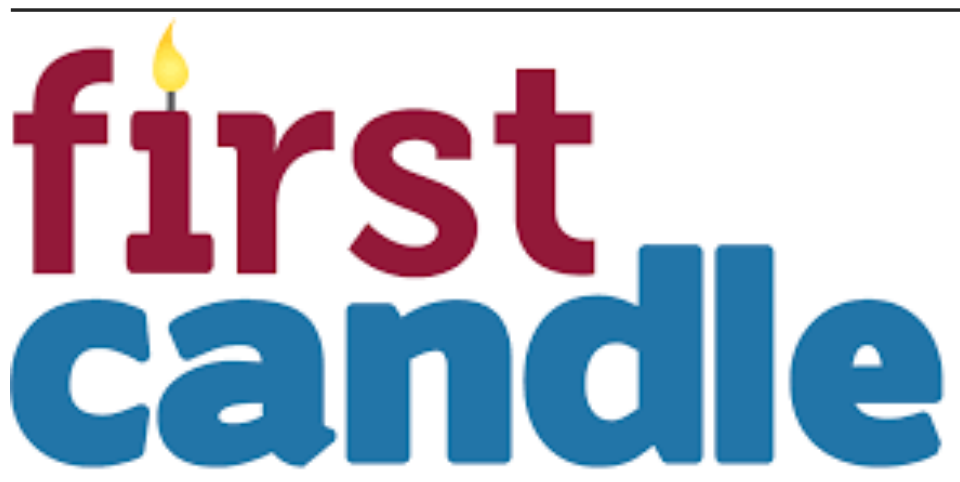

Saving babies. Supporting families.

First Candle's efforts to support families during their most difficult times and provide new answers to help other families avoid the tragedy of the loss of their baby are without parallel.

"In 2020 First Candle hosted a series of focus groups in Georgia, Michigan, and Connecticut to understand the impact of implicit bias, cultural norms, and socioeconomic issues on individuals' access to information about the American Academy of Pediatrics' infant safe sleep guidelines and the choice to adopt them."

In 2020 First Candle hosted a series of focus groups in Georgia, Michigan, and Connecticut to understand the impact of implicit bias, cultural norms, and socio-economic issues on individuals' access to information about the American Academy of Pediatrics' infant safe sleep guidelines and the choice to adopt them.

We had five groups in each state: moms, breastfeeding moms, dads, grandparents, and in-home care providers.

It was among the dads where we discovered the greatest opportunities to increase behavior change regarding safe sleep. Here are some highlights of the insights we gleaned from our focus groups:

Dads are more engaged than ever. Each of the dads spoke passionately about caring for his baby and equally sharing responsibility with mom. They shared stories with each other about how they care for their baby and want to be involved in parenting.

Dads feel marginalized by health care providers. Many dads spoke about how they felt ignored by in-home care providers and medical staff both during the birth and at the pediatrician's office. Because of COVID-19 restrictions, most dads could not even attend prenatal and well-baby visits, but when they did, they felt the conversation and questions were directed towards mom. There was very little acknowledgment of their presence.

\section{"Because of COVID-19 restrictions, most} dads could not even attend prenatal and well-baby visits, but when they did, they felt the conversation and questions were directed towards mom. There was very little acknowledgment of their presence."

Dads do not have enough information. Whether it was due to COVID-19 or the inability to be present during in-home or office visits, dads do not feel they receive much information about safe sleep and breastfeeding. What they learn about safe sleep usually is what they hear from mom second-hand. Because of this, they are unsure about how to support mom in breastfeeding and how to create a safe sleep environment. One dad, an emergency medical technician who had been present at a Sudden Unexplained Infant Death (SUID) event, felt that the safe sleep guidelines are "mere opinions," not facts, and therefore do not necessarily need to be adopted.

Dads always defer to mom. Dads have strong opinions, especially around bed-sharing, but they generally do not share this with mom. Many dads expressed that they "freak out" having a baby in bed with them, and it makes them nervous. But, they believe that

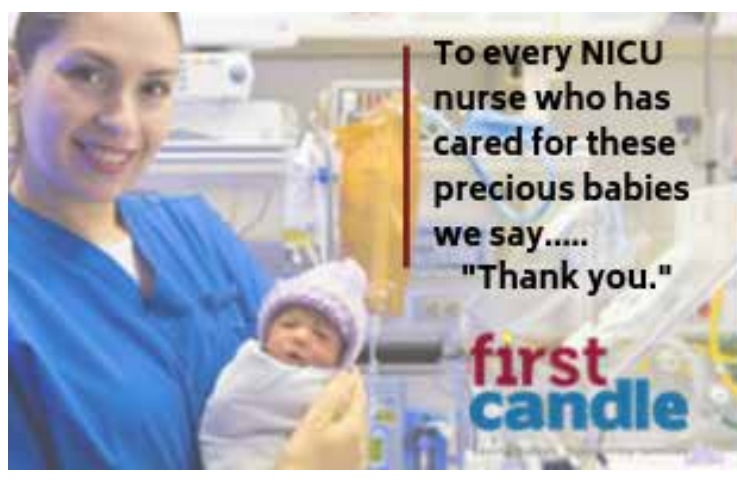

\section{Did you know that premature and low birth weight babies have a $4 \times$ greater risk for SIDS?}

At First Candle we're educating parents, grandparents and caregivers about safer sleep to make sure all babies reach their first birthday. Learn more at firstcandle.org 
"mom knows best" and that their opinions will always be second to mom.

Dads want to receive information in different ways. Dads are less likely to read brochures about safe sleep or breastfeeding, as they feel the information is directed towards mom. It is generally images of mom and baby on brochures, and there is no specific information geared towards dad. They do not see themselves reflected in the materials. Dads also prefer to learn information from other dads. They are less inclined to read materials or listen to a care provider but would be open to listening to recommendations in a group setting of other men in places they frequent, such as gyms, barbershops, and men's organizations.

\section{"Dads also prefer to learn information} from other dads. They are less inclined to read materials or listen to a care provider but would be open to listening to recommendations in a group setting of other men in places they frequent, such as gyms, barbershops, and men's organizations."

\section{How First Candle is responding to these insights.}

Since 2017 we have been conducting our Straight Talk for Safe Sleep program, (1) a train-the-trainer initiative for hospitals, social service agencies, health departments, and in-home care providers. The program works with participants to recognize implicit bias and learn how to engage families in dialogues about the "whys" and "hows" of safe sleep that reflect their lived experiences. This program offers up to five contact hours to nurses.

We are now expanding our focus on how to engage dads, to empower them to support moms in breastfeeding and explore safe sleep options. This will include training providers on how better to address dads during prenatal visits, during birth and follow-up well visits, and establishing programs specifically geared towards dads.

We are creating a Dad Ambassador's group of male community influencers, i.e., coaches, ministers, barbers, media personalities, and sports figures, who can deliver safe sleep messaging to new dads as well as future dads.

To learn more about First Candle's Straight Talk for Safe Sleep program and how to bring it to your hospital, contact Barb Himes, Director of Education and Bereavement Services, at Barb@FirstCandle.org.

\section{References:}

\section{1. https://firstcandle.org/straight-talk-for-infant-safe-sleep/}

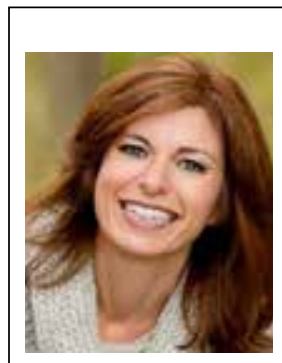

Corresponding Author

Alison Jacobson

Executive Director

Chief Executive Officer

First Candle

49 Locust Avenue, Suite 104

New Canaan, CT 06840

Telephone: 1-203-966-1300

For Grief Support: 1-800-221-7437

www.firstcandle.org

\section{About First Candle}

First Candle, based in New Canaan, CT, is a 501c (3) committed to eliminating Sudden Infant Death Syndrome and other sleeprelated infant deaths while providing bereavement support for families who have suffered a loss. Sudden unexpected infant death (SUID), which includes SIDS and accidental suffocation and strangulation in bed (ASSB), remains the leading cause of death for babies one month to one year of age, resulting in 3,600 infant deaths nationwide per year.

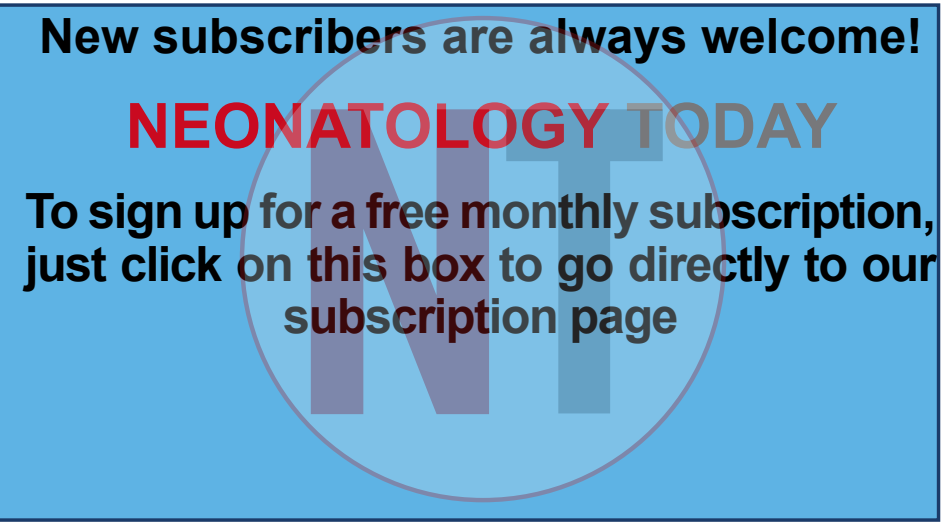

Disclosure: The author is the Executive Director and Chief Executive Officer of First Candle, Inc., a Connecticut not-for-profit 501c3 corporation. 